tion and government programs. Statistical analysis of cotton revenue over time reveals price variability to be the primary source of income risk, while yield variability contributed very little to income risk. The proper choice of risk-management tools then targets price risk rather than yield risk. The two tools that focus on price risk are hedging and forward contracting. The survey results show that $25 \%$ of cotton growers use hedging as a risk-management tool, while only $1.6 \%$ report using crop insurance. This illustrates that producers make appropriate choices among risk-management tools when the source of risk has been identified and several risk-management alternatives exist.

\section{Awareness increasing}

Awareness of risk issues is increasing among California producers. Although producers regard many sources of risk as relevant, it appears from their responses that the attention of lenders is making financial risk paramount among the current risk concerns. The tools available to producers to help manage particular risk sources vary in their effectiveness and availability, and therefore in popularity of use. Many producers indicated that they would be interested in using some of the less available tools, such as hedging and crop insurance, if the tools were available for their crop or livestock enterprise. This indicates latent demand for these tools.

The limited availability of effective risk-management tools severely limits many producers' ability to mitigate risk. At a time when California producers as a whole are becoming more aware of risk concerns, this shortage poses obstacles to risk management. Until tools like crop insurance and futures markets are better tailored to the needs of producers in California, and until producers become better informed about managing income risk, the state's agricultural sector will face unnecessarily high levels of financial stress.

S.C. Blank is Extension Economist and J. McDonald is Research Assistant, Department of Agricultural Economics, UC Davis.

\title{
Vertical drainage may improve soil salinity and moisture
}

\author{
Abdul Karim Yusufzai \ Mark E. Grismer
}

Existing drainage systems in many clay fields of the Imperial Valley have failed to improve soil salinity and to provide moisture conditions favorable to crop growth. In some fields, these problems are exacerbated by saline artesian water from a shallow sand aquifer. This pilotscale field study in the Imperial Valley indicates that vertical drainage is more effective than traditional tile systems in reducing artesian water levels and the overlying clay soil moisture, and should over time also reduce the salinity of these soils. The cost of a widely spaced drainage well system appears comparable to "splitting" existing drainlines.

Drainage systems are commonly used in arid irrigated regions to promote crop growth by controlling water-table depth, root zone salinity and soil aeration. The Imperial Valley is extensively drained with both open ditches and lateral (tile) drainage systems that are designed to provide relief from shallow water tables. As a result of low permeability, the lateral drainage systems are relatively ineffective in many of the heavy clay soils that make up over $40 \%$ of the irrigated valley (California Agriculture, May-June 1988). Improving such drainage systems may be unfeasible because of the high costs associated with narrowly spaced drainlines. Nevertheless, during the past 3 decades growers in parts of the valley have "split" the original drain spacing in the clay soils in an effort to improve their efficacy, with little documentation that any improvement was achieved.

In our previous work in the area, we found that the poor performance of lateral drainage systems may be exacerbated by shallow fine-sand aquifers, which are a source of artesian water into the clay. Lateral drainage systems were not designed for these conditions, although several drainage studies from the 1940s and 1950s describe the widespread occurrence of the finesand aquifer. This artesian water results in relatively high soil moisture in the clay soil profile, and in progressive salinization of the root zone.

Although they have been only briefly considered as an alternative in the Imperial Valley, vertical drainage systems have been successfully installed in other semiarid to arid regions such as the Patterson area of Stanislaus County, the Salt River Valley of Arizona, and parts of the Red River Valley of North Dakota. This report evaluates the potential for and feasibility of developing a shallow vertical or well drainage system for the clay soils overlying fine-sand aquifers in the Imperial Valley as a means of reclaiming or improving these soils for crop production. We also compare the costs associated with lateral and well drainage systems and consider some of the benefits and drawbacks associated with each system.

\section{Imperial Valley setting}

The Imperial Valley is a highly stratified alluvial valley with an arid climate characterized by an average annual rainfall of approximately 3 inches, high summer temperatures, low relative humidity and abundant sunshine. The near-surface layers to depths of 300 feet alternate between sands, silts and clays that interfinger and are cross-bedded in formation. Soil boring by the USGS near the city of El Centro indicates that the silty clay and clay surface soils of the area are underlain by sands at depths rang- 
ing from 13 to 55 feet of land surface and thicknesses of no more than 180 feet. Development of this sand aquifer as a potential domestic or industrial source of water is limited by the relatively high salinity of the groundwater (5 to 10 times that of available Colorado River water) and the lack of need for additional water supplies. However, it was found that the transmissibility of the sand aquifer is moderately high, on the order of 100 to 10,000 gallons per day per foot (gpd/ft), and that production wells could easily yield in excess of 100 gallons per minute (gpm). Similarly, in a detailed study at the UC Desert Research and Extension Center (DREC), referred to locally as the Meloland area, we found a fine-sand aquifer underlying the clay soil at depths of less than 6 feet of land surface, with a thickness in excess of 20 feet and a transmissibility of roughly $1,500 \mathrm{gpd} / \mathrm{ft}$. The salinity of the shallow groundwater ranged from 5 to $6 \mathrm{dS} / \mathrm{m}$ (deciSiemens per meter equivalent to the old unit of millimhos per centimeter).

In both cases the transmissibility of the sand aquifer, although not exceptionally large, is sufficient to develop vertical drainage systems. However, the groundwater quality is relatively poor. With careful management this groundwater could be applied to salttolerant crops, or blended with Colorado River water, but eventually the pumped groundwater would require disposal via the surface drainage canals to the Salton Sea.

This study was prompted in part by the fact that soil salinity in a clay field (area 70 of the UC DREC) has remained practically invariant over the past 30 years of record despite continuous lateral drainage at a depth of 6 feet and several leaching studies involving continuous and intermittent ponding and excess irrigations. The soil profile salinity reaches a maximum value at a depth of roughly 5 feet, corresponding to the pressure head (water elevation) of the artesian aquifer. Because we had a considerable data set for this site and we found it to be representative of many areas in the valley, we used the characteristics of this site as our base conditions with

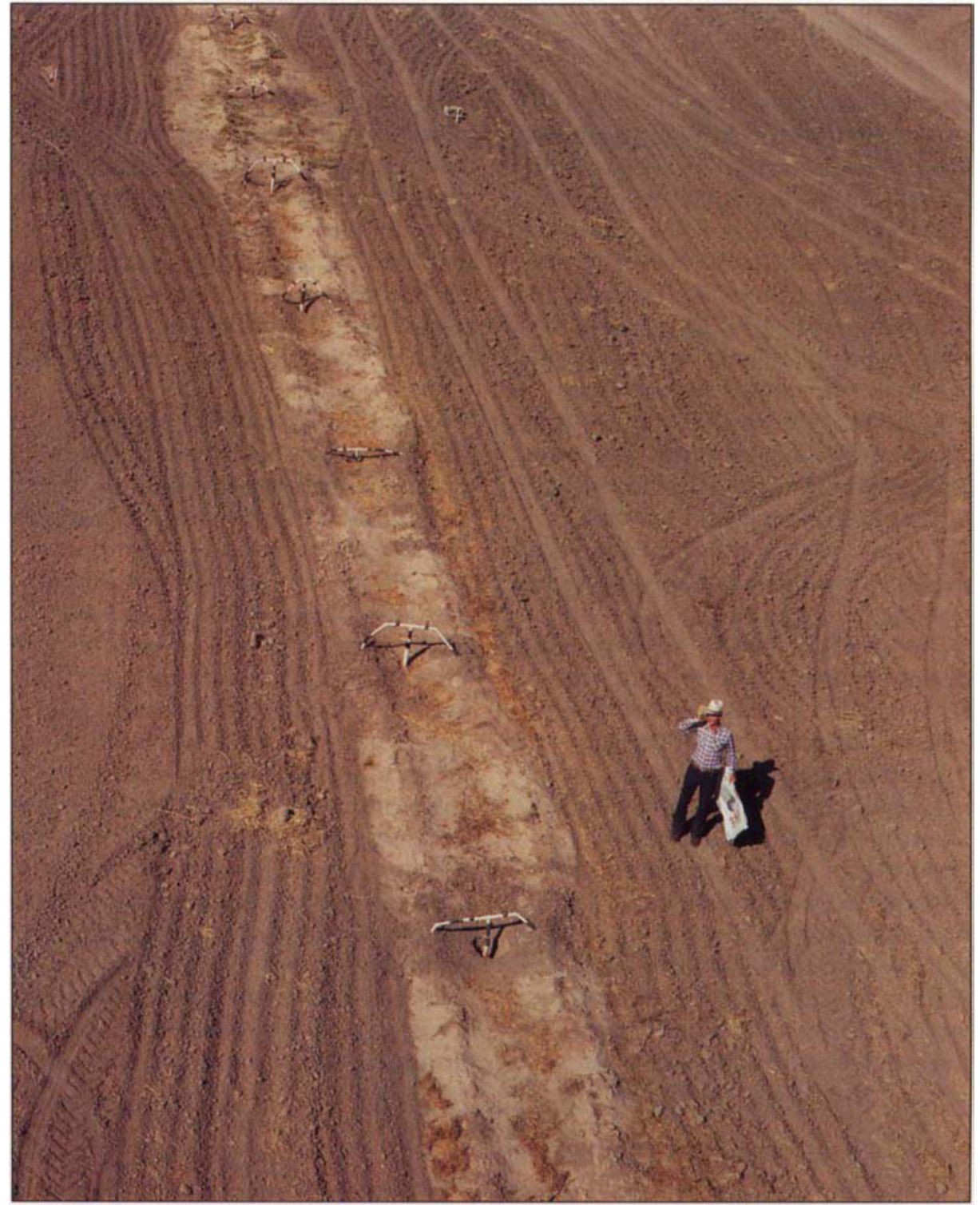

In many clay fields of the Imperial Valley, vertical drainage systems may be more effective than existing lateral drainage systems. This pilot vertical drainage system was less expensive to install and its net annual cost was comparable to traditional tile drainage systems.

which to compare the performance of different vertical and lateral drainage systems.

\section{Drainage system performance}

The design objective of both lateral and vertical drainage systems is to improve root-zone soil aeration and salinity through control of the water-table depth in the soil. The performance of these systems is typically evaluated in terms of the extent to which control of the water table at a desirable depth for crop production is achieved. Unfortunately, the criterion of water-table depth may not adequately describe the performance of the drainage system in terms of salinity control (California $\mathrm{Ag}$ riculture, November-December 1990).
From the salinity control perspective, it is appropriate to gauge the performance of the drainage system in terms of the efficiency with which the system extracts root zone drainage, where root zone drainage is that fraction of the applied water not used by the crop or lost by evaporation. This efficiency depends on several factors related to the hydrogeologic setting of a lateral drainage system, such as drain depth and spacing, soil permeability and aquifer depth. The drainage efficiency of lateral drainage systems can be very low, with the larger fraction of the root zone drainage bypassing the drainlines. In a vertical drainage system, the extraction wells control the shallow groundwater sys- 
tem in such a fashion as to capture the root zone drainage, as well as some regional groundwater flows. Despite the differences in performance, both lateral and vertical drainage systems design involves the use of basic groundwater flow equations to determine the minimum spacing of drain lines or drainage wells necessary to maintain the water table at a desirable depth while capturing root zone drainage.

Assuming the soil profile characteristics of the UC DREC site as representative of a 640-acre (1 square mile) field, we determined lateral and vertical drain spacings from applicable spacing formulae and groundwater flow models, respectively. Taking the design water-table depth of at least 4 feet and a lateral depth of 6 feet, and ignoring upward flow to the drainlines from the artesian aquifer, lateral drain spacings from the formulae of Donnan, Hooghoudt and Ernst yielded lateral spacings of 40 to 160 feet. The Imperial Irrigation District has historically recommended a lateral spacing of approximately 100 feet for valley soils, but has more recently suggested that a 50-foot lateral spacing for the clay soils would be more effective.
Although similar in concept to the lateral system design, vertical or well drainage-system design involves more complex equations or computer modeling and the choice of either different well-field layout patterns of a simple grid or the more efficient triangular pattern, which is potentially more difficult to install. Because of the variable thickness and large area of the shallow, fine-sand aquifer in the Imperial Valley, we chose a vertical drainage system design based on the "skimming well" concept used on islands for the extraction of fresh water above sea water, in a triangular pattern layout. This design involves a number of relatively shallow wells connected by a disposal pipe network, as compared to the more widely spaced individual high-production wells commonly used for vertical drainage. Based on computer simulation studies for the finesand aquifer at the UC DREC, the possible well spacings ranged from 600 to 1,400 feet at well depths of less than 50 feet and flow rates of up to $250 \mathrm{gpm}$. per well.

In both the lateral and vertical drain scenarios, the costs associated with system installation increase with de-

TABLE 1. Lateral drainage system costs for collector drains at 68-foot spacing and 6-foot depth on a 640 -acre field

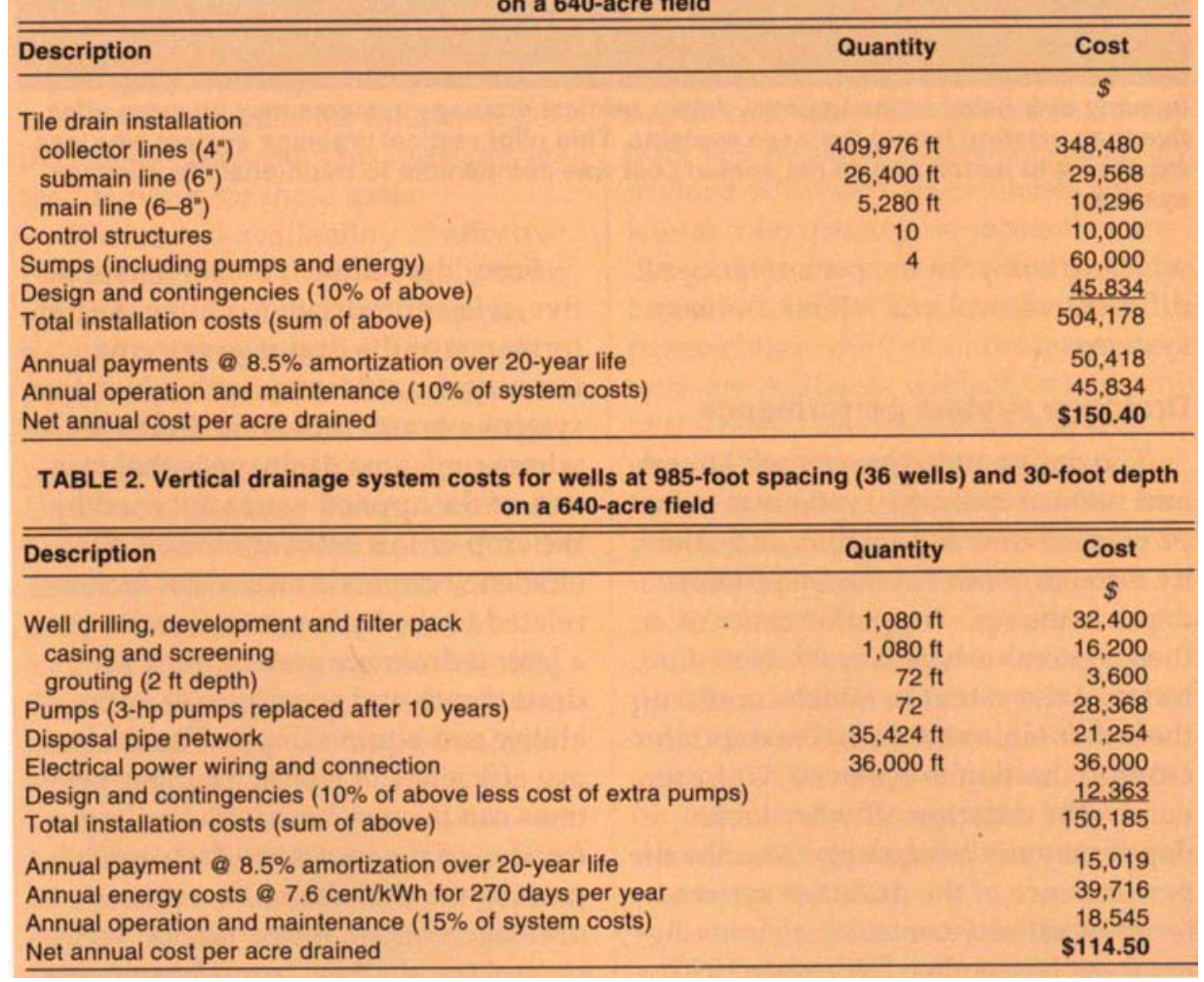

creasing spacing, and the design problem becomes one of selecting a system with adequate performance in terms of water table and salinity control for the least cost.

\section{Comparison of costs}

The costs of a relief, or lateral, drainage system are primarily associated with installation of the drainlines and the number of control structures, such as manholes and sumps. For a 1square-mile field, the least expensive lateral drain layout includes a series of parallel collector lines, at an appropriate spacing, draining into submains that drain into a telescoping collector drain that increases in diameter as the number of submains draining into it increases. Control structures for maintenance are often located at the junction of the submain and collector drains. The collector drain flows enter drain sumps, eventually discharging into district drainage canals. For the purposes of this analysis, we obtained 1992 cost figures from local contractors and from the Imperial Irrigation District. Table 1 summarizes costs for the lateral drainage system with a 68 -foot spacing, and figure 1 illustrates how drainage system costs depend on drain spacing.

The costs of the well drainage systems are primarily associated with the pump and well installation, the pipe network necessary to remove pumped drainage from the field and the energy costs associated with pumping. The well field layout is in a triangular pattern in the 1-square-mile field, with rows of individual wells that either discharge into a PVC collection pipe that eventually enters a mainline pipe discharging to a district canal, or discharge directly to a canal from the field. Each well would be pumped by a dedicated submersible pump in order to minimize maintenance problems and surface obstructions. Because there is only limited well drilling in the Imperial Valley and local contractors don't exist, we used well drilling cost figures from contractors in Yolo County and parts of the San Joaquin Valley. We assumed that if drainage well installation projects were to develop in the Imperial Valley, a drilling 
contractor business would be established, with rates similar to those in other alluvial valleys. Moreover, we found that after penetrating the clay layer, a simple tractor-mounted spray jet nozzle was adequate to install the wells. We also noted that the rather shallow depths of the proposed well systems may allow more rapid installation, by drive-point methods or by a modified jetting apparatus, at much lower costs than are assumed here. Typically, as the well spacing increases a greater pumping rate (gpm) is required to maintain the minimum water-table depth. Table 2 summarizes costs for the vertical drainage system with a 985-foot spacing, and figure 2 illustrates how vertical drainage system costs depend on well spacing.

The drainage system costs shown in figures 1 and 2 indicate that the vertical drainage system costs are less than those of lateral drainage systems for drainline spacings less than approximately 65 feet (the maximum recommended spacing for clay soils). The primary difference between the two types of systems in terms of annual costs is that the vertical system is considerably less expensive to install but has greater operating costs associated with energy (electrical power) and maintenance. From the initial investment perspective, the vertical drainage system is competitive; however, in many fields of the valley, lateral drainage systems already exist and the cost of "splitting" the existing drainlines would be similar to that of installing drainlines at the 126-foot spacing, or approximately $\$ 95$ per acre. At this cost, only the most widely spaced well system (1,400-foot spacing and 50-foot depth) may be competitive. The differ-

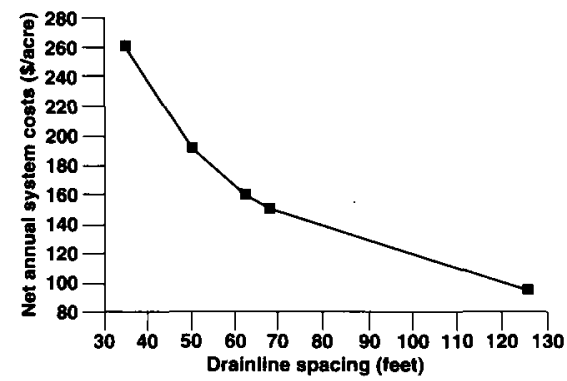

Fig. 1. Lateral drainage system costs ence in performance of the two types of system may be the deciding factor.

It should be noted that these cost comparisons assume that the grower would obtain external financing for the drainage project. Use of internal funds would require a smaller rate of return, which would favor the lateral drainage systems.

\section{Vertical drainage systems}

In order to evaluate the practicality of vertical drainage, and in an effort to improve soil moisture and salinity conditions in the clay soils at the UC DREC, we installed a pilot-scale drainage well system in area 70 to evaluate vertical drainage feasibility in the field. The well system consists of eight 2-inch-diameter wells skimming water at depths of 15 to 18 feet and pumping at a rate of 1 to $2 \mathrm{gpm}$ per well. The well field has lowered the artesian water level below the clay soil to distances in excess of 120 feet away, as well as reducing soil moisture in the clay. The system is roughly equivalent to a single 6-inch-diameter well pumping at 10 to $15 \mathrm{gpm}$ and draining 3 to 4 acres of land. As a result of increased water movement through the clay, we anticipate reduction in soil salinity. So far, after 12 months of continuous pumping, small declines in salinity have been observed. After some difficulties associated with the initial installation of the well system, the system has operated smoothly with only regular maintenance ( 2 hours) of the pump and fittings every 6 weeks. Such maintenance would not be required for the submersible pumps used in the cost estimates given here.

The limitations of the pilot-scale system are the relatively small-diam-

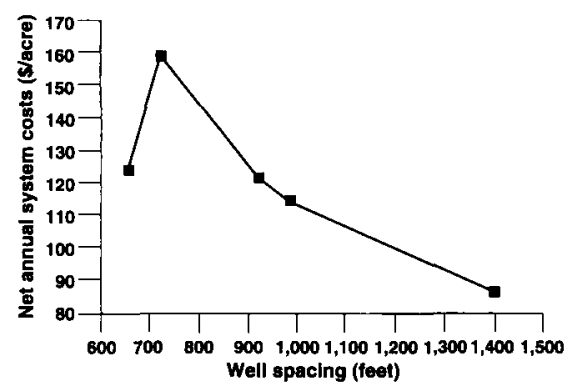

Fig. 2. Vertical drainage system costs eter wells and shallow depths. However, the system performance exceeds that of the existing lateral drainage system (initially installed in 1963 and replaced in 1988) in terms of reducing soil moisture in the clay and, in due time, the soil salinity. The primary drawbacks of the pilot-scale system, or of any of the proposed vertical drainage systems, are the need for electrical power in the field and the land required for the wells and disposal pipe network. These inconveniences can be reduced by selecting the largest well spacing appropriate for the hydrogeologic conditions of the field and by burying the disposal pipe and wiring network in the field. In addition, the vertical drainage system would require regular maintenance that the lateral systems do not require.

\section{Summary and conclusions}

In many clay fields of the Imperial Valley, vertical drainage systems may be more effective than existing lateral drainage systems. We evaluated the economic feasibility of the vertical systems by comparing their costs with those of the lateral systems. Based on projected costs for both drainage systems at installation, vertical drainage systems are much less expensive to install and have a net annual cost that is comparable to that of the traditional tile drainage systems. Computer simulation and pilot-scale field studies indicate that the vertical drainage system is more effective than the traditional tile systems in reducing artesian water levels and the overlying clay soil moisture, and should over time also reduce the salinity of these soils. Finally, it appears that a widely spaced drainage well system is similar in cost to "splitting" the existing drainlines, and if a groundwater drilling business is established in the Imperial Valley, vertical drainage may become a cost-effective and desirable alternative for improving saline clay soils in the valley.

A. K. Yusufzai is Associate Engineering Geologist, Regional Water Quality Control Board, San Francisco Bay Region and M. E. Grismer is Associate Professor, $\mathrm{Hy}$ drologic Science, UC Davis. 